\title{
EFEITO DA ADIÇÃO DO FERMENTO NATURAL SOBRE A CONTAGEM DE BACTÉRIAS LÁTICAS EM QUEIJO MINAS ARTESANAL DO SERRO
}

\section{Effect of natural starter addition on lactic acid bacteria counts in traditional Minas of Serro}

\author{
Virgínia Nardy Paiva , Ana Luisa Ferreira Simões Cunha ${ }^{I}$, \\ Roberta Ribeiro da Cruz Cangussu ${ }^{l}$, Denise Sobral ${ }^{2}$, \\ Rogério Marcos de Souza ${ }^{l}$, Maximiliano Soares Pinto ${ }^{1 *}$
}

\begin{abstract}
RESUMO
Os queijos Minas artesanais possuem grande importância econômica, social, ambiental e política para o estado de Minas Gerais, sendo o responsável pelo sustento direto e indireto de mais de 35 mil famílias. O fermento natural é utilizado pela grande maioria de produtores na forma de soro fermento ou porções de queijos fabricados anteriormente. Todavia o seu uso é indiscriminado o que contribui para a descaracterização do queijo. Até o presente momento não existem estudos envolvendo a utilização do fermento natural na fabricação de queijos Minas artesanais. O objetivo deste estudo foi avaliar o efeito da adição de fermento natural sobre as contagens de bactérias láticas do queijo Minas artesanal do Serro ao longo de 60 dias de maturação. Foram analisados queijos fabricados com e sem fermento natural de três diferentes produtores nos tempos: 8, 20, 40 e 60 dias de maturação, em três repetições. Os resultados mostraram que não houve diferença na contagem de bactérias láticas nos queijos fabricados com e sem fermento natural após oito dias de fabricação. Embora não tenha sido encontrada diferença nas contagens de bactérias láticas dos queijos, certamente há diferença qualitativa na microbiota presente dos queijos provenientes dos dois tratamentos, uma vez que a concentração de sal do fermento natural seleciona certos grupos de bactérias láticas. Estudos de caracterização da microbiota devem ser feitos para que o uso do fermento natural tenha base científica.
\end{abstract}

Palavras-chave: maturação; microbiota; soro fermento.

1 Universidade Federal de Minas Gerais (UFMG), Instituto de Ciências Agrárias, Av. Universitária, 1000, bairro Universitário, 39404-006, Montes Claros, MG, Brasil. E-mail: maxonze@yahoo.com.br

2 Empresa de Pesquisa Agropecuária de Minas Gerais (EPAMIG), Instituto de Laticínios Cândido Tostes, Juiz de Fora, MG, Brasil.

* Autor para correspondência.

Recebido / Received: 10/06/2016

Aprovado / Approved: 29/06/2016 


\begin{abstract}
Traditional Minas cheeses have great economic, social, environmental and political importance for the state of Minas Gerais, being responsible for the direct and indirect sustenance of more than 35 thousand families. The natural starter is used by the majority of producers in the form of whey starter or portions of cheeses made previously. However, it indiscriminated use contributes to mischaracterization of the cheese. Until the present moment there are no studies involving the use of natural starter in the manufacture of traditional Minas cheese. The aim of this study was to evaluate the effect of adding natural starter on the counts of lactic acid bacteria from traditional Minas cheese of Serro over 60 days of ripening. We analyzed three cheeses made with and without natural starter by three different producers at times: $8 ; 20$; 40 and 60 days of maturation in two replications. The results showed no difference in the count of lactic acid bacteria in cheese made with and without natural starter after sixty days of ripening. Although no difference was found in the lactic acid bacteria of cheese counts, surely there is a qualitative difference in the microbiota of cheese from the two treatments since the natural yeast salt concentration selects certain groups of lactic acid bacteria. Microbiota characterization studies should be conducted so that the use of natural starter has scientific basis.
\end{abstract}

Keywords: ripening; microbiota; whey starter.

\section{INTRODUÇÃO}

Os queijos Minas artesanais estão em constante processo de caracterização pelas Associações dos Produtores e, ou Cooperativas de cada região em parceria com a Empresa de Pesquisa Agropecuária de Minas Gerais (EPAMIG) e a Universidade Federal de Minas Gerais. As características físicas, físico-químicas e o processo de fabricação estão em fase final de avaliação pelos produtores das regiões do Cerrado, Araxá, Canastra e Serro. Os processos de caracterização das outras regiões recentemente incorporadas como sendo regiões produtoras tradicionais estão na fase inicial.

Atualmente o queijo Minas artesanal (QMA) do Serro possui as suas características físico-químicas e físicas caracterizadas pela Associação dos Produtores Artesanais do Queijo do Serro (Tabela 1).

Segundo a APAQS (2006), o leite cru deve ser obtido da ordenha completa, manual ou mecanizada, feita uma ou duas vezes por dia (manhã e tarde) das vacas em lactação. Para a retirada do leite usa-se o sistema de bezerro ao pé ou o sistema da vaca sem o bezerro.

Após a ordenha, o leite é filtrado em tecido de algodão ou nylon. Somente $37 \%$ das propriedades avaliadas fazem uso deste utensílio. $\mathrm{O}$ decreto $\mathrm{n}^{\circ} 44.864$ de 1 de agosto de 2008 preconiza filtros de aço inoxidável ou plástico com espaçamento de 10 a 15 meshes para a primeira coagem ainda na sala de ordenha e de 60 a 90 meshes para a segunda coagem no tanque de fabricação (MINAS GERAIS, 2008).

A prática de adição de parte do fermento natural no fundo do tanque de fabricação, ainda durante a ordenha já inicia a fermentação do leite pela microbiota existente no fermento, antes da adição do coalho. Algumas propriedades isoladas utilizam queijo ralado no fundo do tanque, em substituição ao fermento natural tradicional objetivandose também direcionar a fermentação. Pinto 
(2004) verificou quantidades que são utilizadas que variam de 100 a $500 \mathrm{~mL}$ de fermento natural para cada 100 litros de leite. Essa variação é maior no estudo feito pela APQS (33 a $2300 \mathrm{~mL}$ ).

Machado et al. (2004) não mencionam a quantidade média de fermento natural utilizado na fabricação do queijo Minas artesanal do Serro. Furtado (1980) relatou o uso de um a dois litros de fermento natural para cada 100 litros de leite na fabricação de queijos artesanais, quantidade inferior a utilizada atualmente.
O uso do fermento natural é prática comum em pelo menos quatro das cinco tradicionais regiões produtoras de queijo em Minas Gerais. Entretanto, não existem estudos científicos comprovando a necessidade do uso desse fermento. Qualquer fermento microbiano é utilizado para direcionar uma fermentação, se o mesmo contiver maiores concentrações de culturas daquelas contidas no meio onde será adicionado. Estudos recentes mostraram que a maior concentração de bactérias fica retida no queijo e não no soro (PINTO et al., 2009; PINTO et al.,

Tabela 1 - Características do Queijo Minas artesanal do Serro

\begin{tabular}{|c|c|c|}
\hline Características & Classificado & Desclassificado \\
\hline Formato & $\begin{array}{l}\text { Cilíndrico, reto ou ligeiramente } \\
\text { abaulado nas laterais com } 12 \text { a } 14 \\
\mathrm{~cm} \text { de diâmetro e } 05 \text { a } 06 \mathrm{~cm} \text { de } \\
\text { altura. }\end{array}$ & Presença de ângulos vivos. \\
\hline $\begin{array}{l}\text { Cor da } \\
\text { Casca }\end{array}$ & $\begin{array}{l}\text { Branca para os queijos frescos e ama- } \\
\text { relada para os queijos maturados. }\end{array}$ & Presença de outras cores. \\
\hline $\begin{array}{l}\text { Aspecto } \\
\text { da Casca }\end{array}$ & Lisa. & $\begin{array}{l}\text { Casca vermiculosa e com mofos. } \\
\text { Casca com proteólise. }\end{array}$ \\
\hline $\begin{array}{l}\text { Aspecto } \\
\text { da } \\
\text { da Massa }\end{array}$ & $\begin{array}{l}\text { Massa fina, homogênea e com pou- } \\
\text { cas olhaduras mecânicas. }\end{array}$ & $\begin{array}{l}\text { Massa não maciça, granulosa, com } \\
\text { excesso de olhaduras mecânicas e } \\
\text { de fermentação. }\end{array}$ \\
\hline $\begin{array}{c}\text { Cor } \\
\text { da } \\
\text { Massa }\end{array}$ & $\begin{array}{l}\text { Branca à ligeiramente amarelada } \\
\text { na maturação. }\end{array}$ & $\begin{array}{l}\text { Heterogeneidade na cor da massa } \\
\text { (manchas, diferença de cor entre o } \\
\text { centro e as bordas). }\end{array}$ \\
\hline Textura & $\begin{array}{l}\text { Poucas olhaduras mecânicas ou } \\
\text { de fermentação, pequenas, bem } \\
\text { distribuídas na massa. }\end{array}$ & $\begin{array}{l}\text { Excesso de olhaduras mecânicas ou } \\
\text { de fermentação. }\end{array}$ \\
\hline Peso (g) & $\begin{array}{l}\text { Máximo: } 1250 ; \quad \text { Média: } 945,13 \text {; } \\
\text { Mínimo: } 725 .\end{array}$ & $\begin{array}{l}\text { Fora dos limites máximos e mí- } \\
\text { nimos. }\end{array}$ \\
\hline
\end{tabular}

FONTE: APAQS (2006). 
2011; TEODORO, 2012; SOBRAL et al., 2013).

Sendo o fermento natural o soro coletado dos queijos, teoricamente não há necessidade adicioná-lo ao leite cru, para aumento da concentração da microbiota endógena, já que as concentrações microbianas são equivalentes.

Diante disso, o objetivo deste trabalho foi investigar o efeito da adição do fermento natural sobre a contagem de bactérias láticas dos queijos Minas artesanais da Região do Serro.

\section{MATERIAL E MÉTODOS}

De acordo com os critérios de adequação de instalação, sanidade do rebanho, as Boas Práticas de Fabricação, higiene na ordenha, salubridade da queijaria e o processo de fabricação em si, foram escolhidas três unidades produtoras de queijo Minas Artesanal do Serro localizadas no próprio município.

Foram realizadas contagens de bactérias láticas (BAL) de queijos fabricados com e sem adição de fermento natural, adicionados juntamente com o coalho, de três diferentes unidades produtoras em três repetições, perfazendo assim um total de 18 queijos. Os queijos foram avaliados nos tempos 8, 20, 40 e 60 dias de maturação.

As contagens de BAL foram conduzidas utilizando-se ágar MRS (Oxoid Ltd. Basingstoke, England), incubado em anaerobiose a $37^{\circ} \mathrm{C} / 48 \mathrm{~h}$ de acordo com Pinto (2008). Foram selecionadas cinco colônias de cada placa para prova de catalase e coloração de Gram. Culturas Gram positivas (cocos ou bacilos) e catalase negativas foram consideradas BAL. Os resultados foram expressos em UFC/g ou $\mathrm{mL}$ em função do número de colônias confirmadas e da diluição inoculada.

O experimento foi feito em delineamento inteiramente casualizado, sendo o tempo e o uso do fermento natural os fatores estudados. Os logaritmos das contagens foram analisados adequadamente por meio de regressão linear e, ou, por análise de variância, quando foi o caso. Para análise de regressão foram aceitos os modelos que apresentaram nível de significância igual ou menor que $5 \%$ para modelo. As análises estatísticas foram realizadas com o auxílio do programa Statistical Analysis System (SAS) versão 9.1.

\section{RESULTADOS E DISCUSSÃO}

As contagens de BAL diminuíram de forma significativa em função do tempo (Figura 1). Tal fato ocorre naturalmente durante a maturação, processo que ocorre nos queijos onde serão desenvolvidas características sensoriais e a textura do produto. Conforme objetivo final de qualidade, cada tipo de queijo, possui um período de maturação adequado, onde ocorrem transformações no âmbito físico, bioquímico e microbiológico no produto (PERRY, 2004).

Os coeficientes angulares das curvas referentes às contagens de BAL em queijos com e sem fermento não diferiram entre si ( $p>0,05)$ evidenciando que não houve diferença nas contagens de BAL dos dois tratamentos, dentro do período estudado, como pode ser observado na Figura 1. Pode-se inferir com estes resultados que nas condições em que o experimento foi conduzido a utilização do fermento natural não ocasionou em aumento de contagens de BAL nos queijos durante 60 dias de maturação.

Quando as contagens de BAL nos queijos foram submetidas à análise de variância observou-se, considerando os tempos isoladamente, que a utilização do fermento também não ocasionou aumento das contagens de bactérias láticas em cada tempo $(\mathrm{p}>0,05)$. Todavia não se avaliou qualitativamente a microbiota endógena dos queijos neste trabalho, pois ainda que não possua efeito quantitativo nas contagens de BAL, há de se considerar uma diversificação da 
microbiota predominante entre os dois tratamentos ao longo do tempo de maturação.

A coleta do fermento endógeno é feita logo após a salga do queijo e é mantido em temperatura ambiente até o dia seguinte, quando é utilizado. Nestas condições, outros microrganismos contribuem para valores médios de acidez e $\mathrm{pH}$, propiciando o crescimento não só de BAL, mas também de leveduras, fungos filamentosos e também potenciais patógenos como Staphylococcus aureus e Escherichia coli.

Sendo assim, outros fatores podem contribuir para a variação de sobrevivência de BAL em queijos como, por exemplo, a contaminação por outros microrganismos. Estudos mostram que contaminações verificadas nos queijos podem interferir na ação do fermento natural ao longo do período de maturação, no entanto, interferem principalmente no período em que o queijo está fresco (BORELLI, 2002; PIMENTEL FILHO et al., 2005; NÓBREGA, 2007).

A composição da microbiota endógena varia entre as regiões que produzem QMA e até mesmo entre os produtores de uma mesma região. Por exemplo, no fermento endógeno utilizado na fabricação do queijo Minas artesanal da Canastra predominam bactérias láticas dos gêneros Lactococcus e Lactobacillus (L. plantarum e L. casei); já no fermento endógeno da região do Serro, predominam os gêneros Lactococcus e Streptococcus (SANTOS, 2010; DORES ; FERREIRA, 2012; DORES et al., 2013).

A concentração de sal $(\mathrm{NaCl})$ do fermento também interfere e modula sua microbiota e, consequentemente, a microbiota do queijo. A quantidade de sal $(\mathrm{NaCl})$ adicionada varia de acordo com o produtor e com a época do ano, sendo que, em períodos onde a contaminação dos queijos é maior, geralmente no período das águas, adiciona-se uma maior quantidade de sal, na tentativa de inibir o crescimento microbiano indesejável (NÓBREGA 2007; RESENDE, 2014).

Estudos estão sendo feitos no sentido de confirmar ou não se queijos fabricados com fermento natural possuem um maior teor de ácido lático, devido à atividade acidificante das bactérias sobre a lactose, sendo que, uma maior acidez melhora a atuação do coalho.

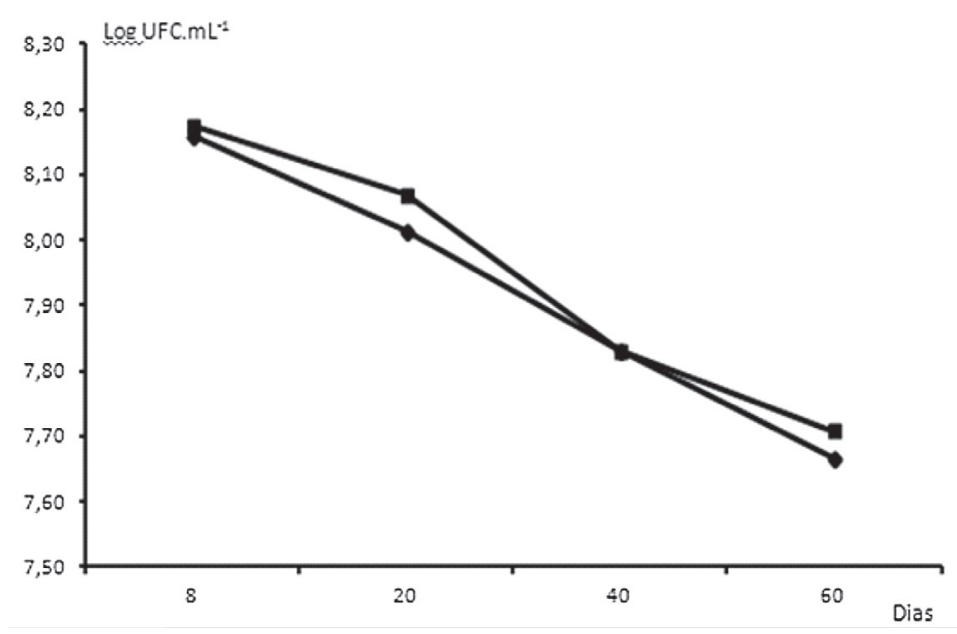

Figura 1 - Contagens de BAL em queijos Minas artesanais do Serro fabricados com (ロ) e sem ( ) fermento natural durante 60 dias de maturação 
Essa microbiota também influencia no maior grau de maturação desse tipo de queijo, que apresenta maior extensão de proteólise (DORES et al., 2013).

\section{CONCLUSÃO}

A adição do fermento natural não influenciou na contagem de bactérias láticas dos queijos Minas artesanais da Região do Serro quando comparado ao mesmo queijo fabricado sem fermento durante os 60 dias de maturação. A utilização do fermento natural é uma prática comum em vários países da Europa onde o leite possui qualidade superior ao leite produzido no Brasil e onde os queijos são reconhecidos internacionalmente. Sendo assim, para criar um padrão de qualidade dos queijos artesanais brasileiros torna-se de suma importância validar e conhecer a função dos fermentos naturais para que possa haver padronização do seu uso baseando-se em estudos científicos, ajustando assim uma escala de produção e contribuindo para a identidade sensorial dos queijos.

\section{AGRADECIMENTOS}

À FAPEMIG pelo apoio financeiro concedido.

\section{REFERÊNCIAS}

APAQS. Caracterização do queijo Minas artesanal do Serro. Associação dos Produtores Artesanais do Queijo do Serro, dezembro, 2006.

BORELLI, B. M. Quantificação dos indicadores higiênico-sanitários e da diversidade de leveduras durante a fabricação do queijo Minas curado da Serra da Canastra-MG. 2002. 109 f. Dissertação (Mestrado em Biologia) - Universidade
Federal de Minas Gerais, Belo Horizonte, 2002.

DORES, M. T. das; FERREIRA, C. L. de L. F. Queijo Minas Artesanal, tradição centenária: Ameaças e desafios. Revista Brasileira de Agropecuária Sustentável (RBAS), v. 2, n. 2, p. 26-34, Dezembro, 2012.

DORES, M., T.; NOBREGA, J. E.; FERREIRA, C. L. L. F. Room temperature aging to guarantee microbiological safety of Brazilian artisan Canastra cheese. Food Science and Technology, v. 33, n. 1, p. 180185, 2013.

FURTADO, M. M. Queijo do Serro: Tradição e história do povo mineiro. Revista do Instituto de Laticínios Cândido Tostes, v. 35 , n. 210, p. 33-36, 1980

MACHADO, E. C. et al. Características físico-químicas e sensoriais do queijo Minas artesanal do Serro, Minas Gerais. Revista Ciência e Tecnologia de Alimentos, v. 24, n. 4, p. 516-521, 2004.

MINAS GERAIS. Decreto 44.864 de 01 de agosto de 2008. Altera o regulamento da lei $\mathrm{n}^{\circ} 14.185$, de 31 de janeiro de 2002, que dispõe sobre o processo de produção de Queijo Minas Artesanal. Minas Gerais, Belo Horizonte, 2 ago. 2008. Diário do Executivo, p. 1.

NÓBREGA, J. E. Caracterização do fermento endógeno utilizado na fabricação do queijo Canastra no município de Medeiros, Minas Gerais, com ênfase em leveduras. 2007. 82 f. Dissertação (Mestrado em Ciência e Tecnologia de Alimentos) - Universidade Federal de Viçosa, Viçosa, 2007.

PIMENTEL FILHO, N. J. et al. Modulação de parâmetros microbiológicos e do $\mathrm{pH}$ pelo cloreto de sódio, no fermento endógeno 
utilizado na produção de queijo Minas artesanal do Alto Paranaíba. Revista do Instituto de Laticínios Cândido Tostes, v. 60, n. 345, p. 295-298, 2005.

PINTO, M. S. Diagnóstico socioeconômico, cultural e avaliação dos parâmetros físicoquímicos e microbiológicos do queijo Minas artesanal do Serro. 2004. 133 f. Dissertação (Mestrado em Ciência e Tecnologia de Alimentos) - Universidade Federal de Viçosa, Viçosa, 2004.

PINTO, M. S. Efeito da microbiota endógena e da nisina sobre Listeria sp. e Staphylococcus aureus em queijo Minas artesanal do Serro. 2008. 84f. Tese. (Doutorado em Ciência e tecnologia de alimentos) - Universidade Federal de Viçosa, Viçosa, 2008.

PINTO, M. S. et al. Programa de apoio ao queijo Minas artesanal produzido no Estado de Minas Gerais. Diagnóstico socioeconômico e cultural dos produtores e avaliação microbiológica do queijo Minas artesanal do Serro. Revista do Instituto de Laticínios Cândido Tostes, v. 59, n. 339, p. 86-92, 2004.

PINTO, M. S. et al. Survival of Listeria innocua in Minas Traditional Serro cheese during ripening. Food Control, v. 20, p. 11671170, 2009.

PINTO, M. S. et al. The effects of nisin on Staphylococcus aureus count and the physicochemical properties of Traditional Minas Serro cheese. International Dairy Journal, v. 21, p. 90-96, 2011.

RESENDE, E. C. Aspectos sensoriais e microbiológicos do queijo Minas artesanal da microrregião Campo das Vertentes. Dissertação (Mestrado em Ciência e tecnologia do leite e derivados) - Universidade Federal de Juiz de Fora. Juiz de Fora, 2014.

SANTOS, A. S. Queijo Minas artesanal da microrregião do Serro-MG: efeito da sazonalidade sobre a microbiota do leite cru e comportamento microbiológico durante a maturação. Dissertação (Mestrado em Zootecnia) - Universidade Federal dos Vales do Jequitinhonha e Mucuri, Diamantina, 2010 .

SOBRAL, D. et al. Efeito da nisina na contagem de Lactococcus e Lactobacillus em queijo Minas artesanal da região de Araxá - MG. Revista do Instituto de Laticínios Cândido Tostes, Juiz de Fora, v. 68, n. 391, p. 5-10, 2013.

TEODORO, V. A. M. Efeito da nisina na multiplicação de Staphylococcus aureus e nas características físico-químicas, reológicas e microbiológicas do queijo Minas artesanal da Serra da Canastra - MG. Tese (Doutorado em Ciência e tecnologia de alimentos) - Universidade Federal de Viçosa. Viçosa, 2012. 